\title{
O TRABALHO E SEUS SENTIDOS ${ }^{1}$
}

\author{
Estelle Morin \\ École des Hautes Études Commerciales, Montreal, Canadá \\ Maria José Tonelli \\ Ana Luisa Vieira Pliopas \\ Fundação Getúlio Vargas, São Paulo, Brasil
}

RESUMO: Desde meados dos anos 1950, pesquisadores têm buscado, por diferentes metodologias, compreender o significado atribuído ao trabalho pelas pessoas em diferentes países. Os resultados obtidos por pesquisadores do grupo Meaning of Work International Research Team ([MOW], 1987) mostraram que o trabalho pode assumir desde uma condição de neutralidade até de centralidade na identidade pessoal e social. O objetivo desta pesquisa é apresentar dados qualitativos sobre os sentidos do trabalho para jovens executivos brasileiros, a partir da abordagem desenvolvida por Morin (2002). Os resultados preliminares desta pesquisa indicam, para a amostra pesquisada, que o trabalho é essencial na vida das pessoas. O principal sentido apontado por este grupo é que o trabalho permite a sobrevivência. Além disso, os dados desta pesquisa indicam que valores como variedade na natureza das tarefas, aprendizagem, autonomia, reconhecimento e segurança também são fundamentais para que o trabalho tenha sentido.

PALAVRAS-CHAVE: sentidos do trabalho; pesquisa qualitativa; jovens executivos.

\section{WORK AND IT'S MEANINGS}

ABSTRACT: Many researches, since the 1950's, seek to comprehend the meaning of work using different methodological approaches. Results obtained by the Meaning of Work group International Research Team ([MOW]) in 1987, in different countries, showed that work could assume different conditions from neutrality to centrality in relation to the subject's personal and social identity. The objective of this research is to present some qualitative data on the meanings of work for young Brazilian managers, using the approach developed by Morin (2002). Preliminary results of this research show that work is essential at the lives of this group, because work is related to survival. Results also indicate that values such as variations on the nature of the tasks, autonomy, recognition and security are also fundamental for a meaningful work.

KEYWORDS: meanings of work; qualitative research; young managers.

O presente estudo aborda, a partir de dados qualitativos obtidos em entrevistas, a questão dos sentidos atribuídos ao trabalho. Desde os escritos da Escola Sociotécnica ${ }^{2}$ em meados dos anos 1950, que vários pesquisadores têm buscado, por diferentes metodologias, compreender o significado do trabalho para as pessoas. A definição de trabalho já foi estudada em diversos países, por pesquisadores do grupo Meaning of Work International Research Team ([MOW], 1987). Esses resultados mostraram que o sentido da atividade de trabalho pode assumir desde uma condição de neutralidade até a de centralidade na identidade pessoal e social. Nesta pesquisa adota-se a perspectiva desenvolvida por Morin (2002), fortemente influenciada pelas pesquisas desenvolvidas pelo grupo MOW, bem como por psiquiatras da linha existencialista, como Viktor Frankl, para quem as ações das pessoas precisam ter sentido. A análise dos sentidos do trabalho não é uma questão unânime e, por este motivo, é necessário colocar os limites deste trabalho. A abordagem de Morin (2002) é uma vertente possível para explorar a questão dos sentidos, já que outras abordagens teórico-metodológicas também buscam sentidos atribuídos pelas pessoas às suas ações, como por exemplo, a abordagem construcionista de Spink (1999) e também de Weick (2000). Essa mesma diversidade de abordagens é encontrada quando se trata da perspectiva sociológica dos sentidos do trabalho, como mostra, por exemplo, Antunes (1995, 1999). Além disso, é necessário destacar que um dos objetivos desta pesquisa foi de buscar dados qualitativos - que precisam ser ampliados - para a construção de um questionário, à semelhança dos utilizados por Morin (2002) no Canadá.

Para este estudo, foram entrevistados quinze alunos do curso de especialização em administração de uma instituição de ensino superior na cidade de São Paulo. O conteúdo das entrevistas foi analisado e os temas recorrentes encontrados foram classificados de acordo com três dimensões: individual, organizacional e social. Os resultados preliminares desta pesquisa indicam que, para a amostra pesquisada, o trabalho é essencial na vida das pessoas já que ele garante a sobrevivência. Além disso, é necessário destacar que um dos objetivos desta pesquisa foi buscar dados qualitativos que permitam, no futuro, a construção de questionários a partir de referências da realidade do país, à semelhança do procedimento qualitativo e quantitativo 
utilizado por Morin (2002) no Canadá. Os resultados também apontam para inúmeras dimensões que deveriam ser consideradas em outras pesquisas qualitativas, como: gênero, idade, região geográfica, função ou cargo exercido na empresa e condição social.

\section{Abordagem teórico-metodológica}

A abordagem teórico-metodológica deste trabalho apóia-se em trabalhos anteriores de Morin (1996, 1997, 2002) que serão descritos mais adiante nesta seção. Vários estudos, em diversos campos do conhecimento, já mostraram como o trabalho ocupa um lugar central na vida das pessoas e das sociedades industrializadas (Antunes, 1995, 1999; Bauman, 1998; Beck, 1999; Castells, 1999; Harvey, 1993; Rifkin, 1995; Schaff, 1995; Sennet, 1999). Neste trabalho, entretanto, nossos interesses se voltam para o entendimento do sentido do trabalho para jovens administradores, na cidade de São Paulo, que possuem curso superior (em geral, Engenharia) e que eram alunos do Curso de Especialização em Administração (CEAG), na Fundação Getúlio Vargas, Escola de Administração de Empresas de São Paulo (FGV-EAESP). De acordo com England e Whiteley (1990), que trabalharam de acordo com as proposições do grupo Meaning of Work (MOW), existem diversos padrões de definição do trabalho. Estes padrões foram classificados de $\mathrm{A}$ à $\mathrm{F}$ e incluem os seguintes aspectos: para o Padrão $\mathrm{A}$, o trabalho acrescenta valor a qualquer coisa, você deve prestar conta do trabalho, você recebe dinheiro para fazer isso; no Padrão $\mathrm{B}$, ao realizar o trabalho existe um sentimento de vinculação, você recebe dinheiro para realizar isso, você faz isso para contribuir com a sociedade; no Padrão $\mathrm{C}$, outros se beneficiam de seu trabalho, você recebe dinheiro para realizar isso, você faz o trabalho para contribuir com a sociedade, o trabalho é fisicamente exigente; no Padrão $D$, você recebe dinheiro para realizar o trabalho, faz parte de suas tarefas, alguém lhe diz o que fazer, não é agradável; para o Padrão E, o trabalho é mentalmente e fisicamente exigente, você recebe dinheiro para fazer isso, mas não é agradável; no Padrão F, existe horário, você recebe dinheiro para fazer isso, faz parte de suas tarefas. Afiliados do grupo MOW (1987), que pesquisaram em mais de oito países, encontraram em todos eles que o elemento salário faz parte da definição de trabalho e que a noção de trabalho é positiva para os padrões A, B e C. Os resultados de investigações conduzidas por membros do mesmo grupo levaram a concluir que a concepção positiva foi maior entre os japoneses, sendo que entre alemães e americanos predominou uma concepção neutra sobre o trabalho.

Morin (1996, 1997, 2002), inspirada nos trabalhos do grupo MOW, pesquisou o sentido do trabalho entre administradores no Quebec e na França, encontrou resultados semelhantes aos já apontados por Emery $(1964,1976)$, Hackman e Oldham (1976) e Trist (1978). Para Hackman e Oldham (1976), três condições contribuem para se obter um trabalho com sentido: variedade das tarefas; identidade com o trabalho e a possibilidade de realizar algo do começo ao fim com resultados; o significado do trabalho sobre o bem das pessoas, da organização e/ou da sociedade. Para estes autores, o trabalho precisa ter seis características para ter sentido: ter variedade e ser desafiador; possibilitar aprendizagem contínua; permitir autonomia e decisão; possibilitar reconhecimento e apoio; trazer uma contribuição social e permitir um futuro desejável.

As pesquisas de Morin (2002), realizadas com duas amostras, uma de estudantes de administração e outra de administradores, trouxeram resultados próximos aos já descritos. Entre os estudantes de administração foram identificados cinco motivos para o trabalho: para realizar-se e atualizar o potencial; para adquirir segurança e ser autônomo; para relacionar-se com os outros e estar vinculado em grupos; para contribuir com a sociedade; para ter um sentido na vida, o que inclui ter o que fazer e manter-se ocupado. De acordo a autora, as características que o trabalho deve ter são consoantes com os motivos que estimulam esses estudantes ao trabalho: é necessário haver boas condições de trabalho (horários convenientes, bom salário, preservação da saúde); oportunidade de aprendizagem e realização adequada da tarefa; trabalho estimulante, variado e com autonomia.

Para os administradores, de nível médio e superior, as pesquisas de Morin (2002) realizadas no Canadá apontam que seis características possibilitam um trabalho que faz sentido. Em primeiro lugar, o trabalho que faz sentido é feito de maneira eficiente e leva a alguma coisa, isto é, é importante que o trabalho esteja organizado e leve a um resultado útil. O trabalho também precisa ser satisfatório em si, ou seja, é necessário haver algum prazer e satisfação na realização das tarefas, resolver problemas, usar o talento e potencial, com autonomia. Além disso, o trabalho precisa ser moralmente aceitável, ou seja, ele deve ser feito de maneira socialmente responsável; os administradores não gostavam de trabalhar em atividades desrespeitosas, injustas ou imorais. $\mathrm{O}$ trabalho também precisa ser fonte de experiências de relações humanas satisfatórias, ou seja, a possibilidade da construção de laços de afeição. $\mathrm{O}$ trabalho que tem sentido possibilita autonomia e garante segurança, ou seja, o trabalho está associado à noção de emprego e à condição de receber um salário que permita garantir a sobrevivência. E, finalmente, um trabalho que faz sentido é aquele que mantém as pessoas ocupadas, isto é, ocupa o tempo da vida, evita o vazio e a ansiedade, tal como apontado por E. Jacques (1978), também ligado à Escola Sociotécnica.

Enquanto abordagem teórico-metodológica, a pesquisa dos sentidos do trabalho para Morin (1996) está vinculada à concepção de psiquiatras existencialistas, Viktor Frankl 
e Irvin Yalom. De acordo com Frankl (1963), as pessoas precisam encontrar sentidos em suas atividades, caso contrário, mergulham numa "frustração existencial". Pauchaunt (1996) argumenta que os pensadores do existencialismo moderno se preocupam com as experiências concretas da existência humana, sejam filósofos, psicólogos e/ou artistas, ao discutir a questão do sentido do trabalho nas organizações.

No que se refere a procedimentos para coleta de dados, os pesquisadores ligados ao grupo MOW (1987) usaram questionários, os pesquisadores da Escola Sociotécnica usaram dados qualitativos de pesquisa e Morin (1996, 2002) usou um procedimento misto, isto é, entrevistas, que, num primeiro momento permitem a obtenção de dados qualitativos, e fornecem a indicação de temas e categorias para a construção de questionários.

Apresentamos na Tabela 1, uma síntese das idéias dos principais pesquisadores que estão sendo utilizados como referência para esta pesquisa.

Cabe considerar nesta discussão, que inúmeros outros autores podem participar deste diálogo sobre os sentidos do trabalho, seja do ponto de vista epistemológico, seja do ponto de vista metodológico. Por exemplo, a produção de sentidos, na perspectiva construcionista (Ibañez, 1997; Spink, 1999), encerra formas de interpretação da reali- dade bem distintas que a abordagem que utilizamos nesta pesquisa.

Uma abordagem que é impossível não destacar, especialmente pela difusão que ela teve, nos últimos quinze anos no Brasil, e por estar diretamente ligada ao tema do trabalho, é a proposta da Psicopatologia e Psicodinâmica do Trabalho, cujo principal expoente é C. Dejours (1987, 1999). Apoiado em conceitos da Psicanálise e da Psicossomática, o autor entende que o trabalho ocupa um papel fundamental na organização da angústia infantil. Assim, o trabalho atua como uma espécie de canalizador das angústias e necessidades (sexuais e agressivas), já descrito por Freud (1997) no processo de sublimação. Para Dejours (1987), o trabalho precisa fazer sentido para o próprio sujeito, para seus pares e para a sociedade. Conforme já apontado pela Escola Sociotécnica, o reconhecimento no trabalho é fundamental para permitir a construção de uma identidade pessoal e social. Este reconhecimento significa a percepção por parte dos pares, dos subordinados e das chefias, o uso da inteligência - a métis - no trabalho (Dejours \& Abdoucheli, 1994). Além disso, o trabalho assume para Dejours e Abdoucheli (1994), um sentido que é a luta pela transformação em algo útil, do sofrimento inevitável que todas as pessoas carregam em decorrência da existência de uma angústia pela incerteza da existência e

Tabela 1. Pesquisas sobre sentidos do trabalho.

\begin{tabular}{ll}
\hline Principais autores & Principais conceitos \\
\hline & O trabalho acrescenta valor a alguma coisa - Padrão A \\
& O trabalho é central na vida das pessoas - Padrão B \\
& O trabalho é uma atividade que beneficia os outros - Padrão C \\
OOW (1987) & O trabalho não é agradável - Padrão D \\
& O trabalho é exigente física e mentalmente - Padrão E uma atividade regular remunerada - Padrão F \\
\hline & O trabalho apresenta variedades e desafiador \\
& O trabalho traz aprendizagem contínua \\
& O trabalho permite autonomia e decisão \\
Emery (1964, 1976) & O trabalho é reconhecido \\
E. Jacques $(1978)$ & O trabalho traz contribuição social \\
& O trabalho pode ser usado como uma defesa contra a angústia \\
\hline & O trabalho é eficiente e produz um resultado útil \\
Há prazer na realização da tarefa & O trabalho permite autonomia \\
O trabalho é fonte de relações humanas satisfatórias & O trabalho mantém as pessoas ocupadas \\
O trabalho é moralmente aceitável \\
\hline Morin $(1996,1997,2002)$
\end{tabular}


fragilidade da vida. Nesta concepção, o prazer no trabalho, fundamental para manutenção da saúde e da normalidade, decorre da transformação do sofrimento em criações reconhecidas no espaço público, seja ele na própria organização ou na sociedade.

Além disso, em nosso país, muitas pesquisas voltam-se para o estudo de processos de saúde-doença no trabalho. São conhecidos, por exemplo, os trabalhos de Alves (1999), Borges (1997), Borsoi (2002), Codo (2002), M. das G. Jacques (2002) e Seligmann-Silva (1994, 1997). Tratase de abordagens críticas sobre os efeitos psicopatológicos do trabalho, que contribuem para o entendimento do sofrimento das pessoas no trabalho. Estas pesquisas reforçam o conceito de que trabalho tem um papel central na organização da identidade e na construção dos sujeitos contemporâneos.

Ainda no contexto de pesquisas brasileiras sobre o sentido do trabalho, deve-se destacar os trabalhos de Lívia Borges (1999), exatamente por se tratar de um estudos feitos no Brasil sobre valores, ideologias e concepções de trabalho presentes na mídia. A autora pesquisou as concepções de trabalho presentes na Folha de São Paulo e na revista Exame, no período entre janeiro de 1995 a junho de 1996, utilizando-se de análise de conteúdo para a construção de temáticas. Foram examinados 60 artigos da revista Exame e 299 artigos do jornal Folha de São Paulo e os resultados apontaram valores individuais e organizacionais. Nota-se que o objetivo da pesquisa foi pesquisar valores e concepções de trabalho, mas não sentido. Entre os valores individuais encontrados na análise da revista Exame, destaca-se: competência, qualificação, sucesso, produtividade, inovação, visão estratégica e autonomia, entre outros. Entre os valores organizacionais apresentados na mesma revista, é possível ressaltar: lucratividade, competitividade, redução de custos, progresso, recompensas econômicas, modernização tecnológica, agilidade administrativa, expansão e globalização. Na análise dos artigos do jornal Folha de São Paulo, os valores individuais encontrados foram os seguintes: qualificação, obedecer, seguir normas, realização, produtividade, auto-suficiência e rapidez, autonomia e sobrevivência. Entre os valores organizacionais, foram percebidos: emprego, recompensas econômicas, progresso, proteção e legalidade, assistência e benefícios, estabilidade no emprego, negociações coletivas e cumprimento das obrigações. Na discussão dos dados, Borges (1999) aponta que há divergências nas concepções de trabalho que emergem destes dois meios de comunicação analisados. Posteriormente a autora continuou pesquisando os significados do trabalho em diferentes contextos e relacionado a outras variáveis (como motivação, por exemplo) na direção de melhor definir o fenômeno (Borges, 1999).

\section{A Pesquisa}

Exploramos quais os sentidos que jovens administradores atribuem ao trabalho. O procedimento de coleta de dados utilizado para a investigação foi por meio de entrevistas semi-estruturadas. O roteiro de entrevistas foi elaborado a partir das pesquisas de Morin (2002), e consistiu de doze perguntas. A pergunta central para os objetivos deste trabalho, entretanto, foi: "para você, um trabalho que faz sentido é...?", de modo que o entrevistado pudesse, livremente, completar a frase com suas idéias. A partir dessa resposta eram explorados possíveis desdobramentos e, na sequiência, a pergunta era, "para você, um trabalho que não faz sentido é:...?", de modo a continuar com o entendimento sobre "o avesso" da questão.

Foram entrevistados quinze alunos do curso de especialização. $\mathrm{O}$ mais jovem respondente tinha 22 e o mais velho, 31 anos. Onze dos entrevistados eram homens e quatro mulheres. Neste grupo, oito eram engenheiros, com várias especializações: engenharia química, mecânica, eletrônica, elétrica, da computação e metalúrgica. Os demais entrevistados tinham formação em direito, economia, letras, tecnologia e farmácia e bioquímica. Apenas um dos entrevistados não estava empregado quando a entrevista foi realizada, porém como possuía mais de sete anos de experiência profissional, foi incluído na pesquisa. Para atender padrões éticos em pesquisa, as entrevistas foram gravadas com o consentimento dos participantes e, posteriormente, transcritas.

A análise do material de pesquisa resultou na seguinte classificação: o trabalho e seus sentidos para o próprio indivíduo, o trabalho e seus sentidos para a organização e o trabalho e seus sentidos para a sociedade. Esses resultados são apresentados a seguir.

\section{Apresentação dos Resultados}

Apresenta-se uma síntese com os temas recorrentes encontrados nesta pesquisa na Tabela 2. Os resultados foram agrupados de acordo com o sentido que o trabalho assumiu para a própria pessoa (dimensão individual); de acordo com o sentido que pode ser encontrado na relação da pessoa com a organização (dimensão organizacional) e de acordo com o sentido que pode ser encontrado na relação da pessoa para com a sociedade (dimensão social). Cada uma destas dimensões será desenvolvida a seguir.

\section{Dimensão individual}

Em relação à dimensão individual foi observado entre os entrevistados vários aspectos: satisfação pessoal, autonomia e sobrevivência, aprendizagem e crescimento, bem como a questão da identidade. Cada um destes aspectos está descrito a seguir. 
Tabela 2. Temas recorrentes.

\begin{tabular}{|c|c|c|c|}
\hline \multirow{2}{*}{ Dimensão } & & \multicolumn{2}{|l|}{ Temas recorrentes } \\
\hline & & Um trabalho tem sentido se... & Um trabalho não tem sentido se... \\
\hline \multirow{10}{*}{$\begin{array}{l}\text { Dimensão } \\
\text { Individual }\end{array}$} & \multirow{3}{*}{ Satisfação pessoal } & $\begin{array}{l}\text { Quem exerce o trabalho sente } \\
\text { prazer, gosta do que faz }\end{array}$ & É enfadonho \\
\hline & & É um desafio a ser superado & $\begin{array}{l}\text { Quem exerce não tem responsabilidade } \\
\text { sobre seu próprio trabalho }\end{array}$ \\
\hline & & $\begin{array}{l}\text { A pessoa percebe sua contribuição } \\
\text { como única e criativa }\end{array}$ & $\begin{array}{l}\text { Quem o exerce não contribui na sua } \\
\text { criação e concepção }\end{array}$ \\
\hline & \multirow{3}{*}{$\begin{array}{l}\text { Independência } \\
\text { e sobrevivência }\end{array}$} & $\begin{array}{l}\text { Remunera financeiramente quem } \\
\text { trabalha }\end{array}$ & \\
\hline & & $\begin{array}{l}\text { Permite que algum dia o indivíduo } \\
\text { alcance qualidade de vida melhor }\end{array}$ & \\
\hline & & $\begin{array}{l}\text { Dá a sensação de independência } \\
\text { financeira e psicológica }\end{array}$ & \\
\hline & $\begin{array}{l}\text { Crescimento e } \\
\text { aprendizagem }\end{array}$ & $\begin{array}{l}\text { Crescimento profissional / } \\
\text { aprendizagem }\end{array}$ & $\begin{array}{l}\text { Não explora o potencial de quem } \\
\text { o exerce } \\
\text { Não há crescimento de quem o exerce }\end{array}$ \\
\hline & \multirow{3}{*}{ Identidade } & Fornece identidade a quem exerce & \multirow{3}{*}{ Há o ócio, se não há trabalho } \\
\hline & & $\begin{array}{l}\text { A empresa onde a pessoa trabalha } \\
\text { é reconhecida }\end{array}$ & \\
\hline & & É símbolo de status & \\
\hline \multirow{5}{*}{$\begin{array}{l}\text { Dimensão } \\
\text { Organizacional }\end{array}$} & \multirow[t]{2}{*}{ Utilidade } & $\begin{array}{l}\text { Quem exerce percebe o processo } \\
\text { do início ao fim }\end{array}$ & \multirow{2}{*}{$\begin{array}{l}\text { Ninguém dá importância } \\
\text { Inútil para a organização }\end{array}$} \\
\hline & & Tem utilidade para a organização & \\
\hline & \multirow{2}{*}{ Relacionamento } & $\begin{array}{l}\text { A pessoa tem oportunidade } \\
\text { de relacionar-se com outros }\end{array}$ & \\
\hline & & $\begin{array}{l}\text { Alguém da organização } \\
\text { dá o reconhecimento }\end{array}$ & \\
\hline & Inserção social & Permite inserção social & \\
\hline Dimensão Social & Contribuição social & $\begin{array}{l}\text { Contribui para a sociedade } \\
\text { É considerado ético e moralmente } \\
\text { aceitável }\end{array}$ & \\
\hline
\end{tabular}

Satisfação pessoal. Os entrevistados expressam que um trabalho que tem sentido dá prazer a quem o exerce, a pessoa gosta de suas atividades, aprecia o que faz. Confirmando este tema, muitos entrevistados dizem que falta sentido no trabalho quando ele é enfadonho. O sentido de satisfação no trabalho está relacionado à contribuição pessoal do indivíduo para o próprio trabalho. Além disso, o trabalho faz sentido se quem o executa tem a sensação de superar desafios e se seu executor percebe sua contribuição e responsabilidade no trabalho executado. A atribuição de sentido ao trabalho relacionado a fatores internos, de gosto pessoal, pode ser observada nas seguintes afirmações dos entrevistados:

Trabalho pra mim... é... primeiramente eu procuro sempre fazer.. alguma coisa que eu goste, pra que sempre saia bem feito, porém não só o que eu gosto, eu consigo fazer bem feito.
[Um trabalho que tem sentido é] aquele que eu tenho prazer.

... quando você faz o relatório que chega lá e faz a diferença dá um prazer assim pra mim enorme... Se eu tô lá eu quero fazer algo, eu quero fazer uma diferença, dar a minha contribuição... não só ganhar o salário... naquele ambiente eu sou o único, naquele ambiente eu faço a diferença... então isso é muito gratificante pra mim.

[Um trabalho que tem sentido é] aquele que você tem liberdade de criar, pode aplicar suas iniciativas...

Autonomia e sobrevivência. Quando questionados a descrever um trabalho que tem sentido, o tema remuneração foi mencionado por todos os entrevistados, mesmo que sempre acompanhado de outro elemento que complementasse o sentido do trabalho. O dinheiro ganho como fruto do trabalho é associado à perspectiva de autonomia e independência do trabalhador. Tal autonomia pode ser pre- 
sente ou projetada ao futuro: o indivíduo se percebe trabalhando muitas horas nos dias atuais para poder progredir na escala hierárquica, passar a receber remunerações maiores e poder conquistar seus sonhos: ter mais tempo disponível, ganhar o suficiente para poder sustentar filhos, adquirir moradia e atingir uma melhor qualidade de vida. Vale notar que a autonomia financeira está também relacionada à liberdade de escolhas, a não depender de outro para tomar suas decisões, como é possível observar nas frases a seguir:

... e o dinheiro não deixa de ter importância, afinal eu quero ganhar muito mais, bem mais, a questão das tarefas faz muita diferença.

... gosto muito do que eu faço, adoro, mas se não me pagarem, amanhã eu não vou mais...

Atualmente o sentido do meu trabalho... é chegar numa posição... que eu me sinta mais... com tranqüilidade..., se eu não trabalhar se eu não aprender.. se eu não crescer.. eu não vou chegar nesse momento que eu espero chegar na minha vida... de ter as minhas coisas... meu apartamento... poder ter filhos...

... no princípio da minha vida eu trabalhava porque eu queria ir embora de casa... aí depois eu precisava aprender mais... e hoje em dia eu trabalho porque... se eu não trabalhar... acho eu entro em depressão. Eu trabalho porque eu gosto, porque eu preciso, porque eu me sinto segura como pessoa, como ser humano... pra ganhar dinheiro também.

... isso me deixa um pouco cansado me faz pensar as vezes tentar procurar outra área, se eu estivesse numa área talvez um nível acima, nível gerencial... na realidade algumas empresas tratam essa posição que eu estou como posição mais gerencial, outras não, se eu tivesse um nível acima talvez eu não comprometesse tanto minha vida particular.

Nenhum dos entrevistados, entretanto, relacionou a percepção de baixa remuneração à falta de sentido do trabalho.

Aprendizagem e crescimento. Os entrevistados relacionam o sentido do trabalho com crescimento profissional e aprendizagem. Os indivíduos demonstraram preocupação com uma eventual estagnação de suas carreiras. A perspectiva de galgar as escalas hierárquicas traz sentido ao trabalho. Este é o crescimento desejado e esperado dentro do mundo organizacional. Porém, acredita-se que a ascensão organizacional ocorra antes para os mais competentes, para os mais aptos. Assim, trabalho com sentido passa a ser aquele que proporciona a aquisição de habilidades e conhecimentos, que permite o aprimoramento de competências do indivíduo. Nas descrições de trabalho sem sentido, os entrevistados mencionam que não faz sentido realizar trabalho que não carregue consigo potencial de crescimento, nem tampouco realizar trabalho que não explore o potencial de desenvolvimento das pessoas.
As entrevistas mencionam:

Desenvolvimento na carreira... tenho possibilidade de crescer... não faço questão de chegar a presidente mas...

... pra minhas expectativas atualmente ele tá de bom tamanho e ele tem uma perspectiva de... crescimento de evolução a carreira, aprendizado e crescimento profissional de uma forma geral, então é um bom emprego.

O aprendizado e crescimento organizacional mencionado pelos entrevistados podem ser característicos do momento de vida das pessoas que compõem a amostra: são jovens em idade, em média têm 27 anos, mas ainda não atingiram postos gerenciais. Todos são estudantes de um curso de especialização em administração noturno. $\mathrm{O}$ fato de profissionais formados em outras áreas buscarem tal especialização pode ser interpretado como uma ambição dos componentes deste grupo em assumir responsabilidades administrativas adicionadas às atividades de seus empregos atuais. Desta forma, o tema aprendizagem e crescimento como elementos que dão sentido ao trabalho traduzem as expectativas deste grupo específico. A superação de desafios e a busca de autonomia também podem ser interpretadas como temas característicos deste grupo: são pessoas muito próximas a assumir responsabilidades gerenciais, que almejam tais posições e, neste caso, buscam ascensão organizacional por meio de superação de desafios. Neste caso, autonomia, pode representar uma característica dos postos mais altos, que são almejados.

Identidade. Mesmo com as mudanças nas relações de trabalho ocorridas desde a última década, há pessoas que encontram na empresa em que trabalham fonte de orgulho, identificação e até identidade:

... eu tenho orgulho de trabalhar na empresa que eu
trabalho, tenho orgulho de trabalhar nas mar.. com
as marcas que eu trabalho, eu tenho vontade... eu
levanto de manhã com muita vontade de trabalhar,
viajar, fica até super tarde, quer dizer tem alguma
coisa que eu não sei exatamente o que é e que... pelo
que eu andei parando pra pensar não é só o salário...
tem alguma outra coisa mas eu não sei identificar o
que é, que me faz ter bastante vontade de trabalhar.
[Tenho orgulho da empresa] porquê é uma empresa
grande reconhecida no mercado, tem marcas famo-
sas, que todo mundo conhece e é mais por isso assim
é realmente reconhecimento e esse orgulho é mais
ligado a reconhecimento.

A declaração do entrevistado deixa claro o grande prazer em trabalhar para uma empresa que fabrica produtos de marcas reconhecidas. Tomando como exemplo a vida organizacional, podemos inferir que a organização contribui significativamente para a identidade das pessoas: trata-se de um exemplo típico da quase totalidade das pes- 
soas que se apresentam tendo a empresa onde trabalham como complemento de seu nome.

Para alguns dos entrevistados, um dos sentidos do trabalho é o status que este fornece: a empresa onde a pessoa trabalha, o cargo que ocupa, os benefícios que usufrui e o dinheiro que ganha são componentes importantes na atribuição de sentido do trabalho.

... então se é algo que você gostaria de fazer, algo que dá um bom status... sim, a pessoa tem vergonha de falar.. mas é verdade você tem uma boa posição né, e é lógico dinheiro também né, remuneração.

Por outro lado, o ócio é mencionado por alguns entrevistados como falta de sentido. Para essas pessoas, o que não faz sentido é o não trabalho, o ócio:

... vejo [trabalho] como uma coisa essencial que eu tenho que fazer não só pra sobreviver, mas em questões monetárias, mas é em questão de ter o que fazer da vida, também não ficar parado vendo TV. Eu gosto de trabalhar.. definitivamente não sou um cara fica... não gosto de ficar muito parado assim sem fazer nada...

Além disso, para alguns entrevistados, o tipo de trabalho realizado pela pessoa teria um importante significado. Dentre os entrevistados há aqueles que declaram que a dona de casa não trabalha, é ociosa, já que não recebe salário em retribuição às suas atividades. Está presente também a declaração de que "há os que trabalham e os que pensam" nas organizações. Tal afirmação pode ser interpretada como falta de apreço pelo trabalho que não seja de tomada de decisão. Assim, se alguém toma decisões, realiza o trabalho intelectual, pode ser diferenciado dos demais.

\section{Dimensão organizacional}

Neste item, surgiram duas características: utilidade e relacionamentos, descritos a seguir.

Utilidade. Um tema recorrente bastante presente entre os entrevistados foi a atribuição de sentido ao trabalho devido a sua utilidade. $\mathrm{O}$ trabalho tem sentido se o produto do trabalho servir a algum propósito. A percepção da utilidade inclui vários temas: desde a produção de medicamentos e de pesquisas em laboratórios, até o relatório que é elaborado por um dos entrevistados e é usado para esclarecer dúvidas em uma reunião. Narrar que um sistema desenvolvido no antigo emprego ainda é utilizado é exemplo de trabalho que faz sentido. De maneira inversa, muitos entrevistados atribuem a falta de sentido do trabalho a sua não utilização:

... você para pra pensar.. se faz sentido realmente o que você esta fazendo se faz sentido pra alguma coisa, se tem um objetivo atrás disso ai... tem coisa que eu faço que as vezes eu... me surpreende... digo pô por que você tá fazendo isso aqui que não vai servir pra nada, não... não tem uma razão de ser.
Além da utilidade, alguns entrevistados mencionam como sentido do seu trabalho a percepção do todo, do processo produtivo do início ao fim. São funcionários da indústria de produção que atribuem sentido e satisfação à observação da transformação de insumos em produto final. A utilização do produto encerraria seu ciclo:

... então eu consigo ver aonde ele começa aonde acaba, porque eu to fazendo aquilo que to fazendo, a importância daquilo... acho que isso é o mais importante.

Relacionamentos. Muitos dos entrevistados associam à utilidade do produto o reconhecimento por alguém da organização desta utilidade. Assim, o sentido do trabalho é dado pelo reconhecimento de alguém, que muitas vezes distingue o trabalho do entrevistado como útil.

Há vários entrevistados que, quando convidados a relatar algum tipo de trabalho com sentido que tenha realizado, mencionam o reconhecimento de seus superiores na escala hierárquica:

Então, dá um prazer enorme, né!! Que até o diretor nosso veio falar: Nossa, muito legal!!!! Dá aquele tapinha nas costas, assim... Eu gosto...

... todo mundo lá pergunta cadê [nome do entrevistado] gostaram de mim ..o sistema ta sendo usado o dono da empresa... que é uma consultoria pequena... me elogia... olha [nome do entrevistado] que seu sistema hoje é vital lá. Eu considero único trabalho mеu que... [fez sentido].

Mas outros tipos de relacionamentos também são mencionados como colaboradores para o sentido do trabalho. Os entrevistados relatam que o trabalho como uma importante fonte de relacionamento entre pessoas:

... mas é um lugar muito agradável, que tem uma pessoa... um pessoal assim é... selecionado a dedo mesmo e que se adaptou com o estilo de trabalho, então é muito bom, muito bom.

... mas tem um lado positivo, é por exemplo a equipe é muito boa, muito integrada, todo mundo é muito amigo, né então isso conta muito, o ambiente muito descontraído, não tenho que... não é uma coisa assim super rígida, tanto como vestuário ou de comportamento assim de... então é um ambiente muito gostoso de trabalho. Todo mundo dentro de sua seriedade, profissionalismo, muito gostoso.

\section{Dimensão social}

Neste aspecto, as entrevistas revelaram duas características: inserção na sociedade e contribuição para a sociedade. Essas duas características serão destacadas a seguir.

Inserção na sociedade. Alguns dos entrevistados descrevem o sentido do trabalho como uma maneira de pertencer ao conjunto social. A formação profissional, o trabalho exercido, a empresa onde o trabalho é exercido e a própria 
remuneração são papéis que permitem ao homem interagir de e com diferentes grupos sociais. Algumas afirmações deixam esta perspectiva mais clara:

... é algo social né... uma vez que se busca... busca... pra você hoje ter lazer pra você se encontrar pra você tá bem consigo mesmo boa parte do seu tempo você vai ter que estar trabalhando né, trabalhando você é útil pra sociedade de alguma forma... e você pode conquistar.. uma posição de desfrutar lazer e desfrutar... proporcionar alguma coisa pra uma família, vislumbrar alguma coisa para o futuro... é meu me sinto parte aí de uma sociedade, então é por isso que eu trabalho.

... realização quanto pessoa, realização profissional, mas provavelmente se eu tivesse uma fonte de renda e ficar assim sem fazer nada... é... acaba que sempre fica afastada da sociedade como um todo.

Contribuição para sociedade. Dentre os entrevistados há aqueles que relatam que um trabalho tem sentido quando presta alguma contribuição à sociedade. Observamos, portanto, que o questionamento quanto ao sentido do trabalho transcende, neste caso, as questões individuais e organizacionais.

[Trabalho que faz sentido é] o trabalho que sinto que estou contribuindo para a sociedade em geral.

Ademais, entre os temas recorrentes observamos a atribuição de sentido ao trabalho considerado ético. Para estas pessoas, um trabalho moralmente inaceitável é um trabalho absurdo.

\section{Discussão dos resultados}

Para o grupo pesquisado, foi possível encontrar resultados semelhantes aos demonstrados na literatura internacional. Mas, há também especificidades que nos pareceram relacionadas ao contexto brasileiro e que mereceriam ser aprofundadas em outras pesquisas. $\mathrm{O}$ primeiro aspecto a ser ressaltado para este grupo é o sentido positivo dado pelos entrevistados ao trabalho: é possível verificar que os entrevistados se enquadram no padrão $B$ da pesquisa do grupo MOW (1987), para o qual o trabalho é central na vida destas pessoas. Não há entre os respondentes alguém que apresente padrões negativos ou neutros segundo os padrões das pesquisas do grupo MOW (1987). Tal resultado não surpreende nossas expectativas, já que é bastante provável esperar que profissionais graduados, estudantes de especialização em administração, que demonstram desejo de alcançar postos mais altos na escala hierárquica das empresas onde trabalham, encarem o trabalho positivamente.

Uma coincidência entre os resultados da nossa pesquisa e os resultados do grupo MOW (1987) é a associação unânime dos entrevistados entre dinheiro e trabalho.
Trabalhoé indiscutivelmente fonte de sobrevivência. Além disso, alguns entrevistados não tinham uma relação tradicional de emprego com a empresa onde realizam seu trabalho, talvez apontando para as novas relações de vínculo entre a empresa e o trabalhador ou talvez retratando o crescimento do trabalho informal presente no contexto do país.

Na dimensão individual, a idéia de satisfação pessoal está presente nos vários autores pesquisados, ainda que de maneiras diferentes. Para a Escola Sociotécnica (Hackman \& Oldham, 1976), o trabalho deve apresentar variedades e ser desafiador; para Morin (2002), o trabalho permite a utilização do talento e do potencial e há prazer na realização da tarefa, enquanto para Dejours (1987) e Dejours e Abdoucheli (1994), o trabalho atende necessidades físicas, simbólicas e psíquicas das pessoas. Quando os entrevistados desta amostra dizem: "quem exerce o trabalho sente prazer, gosta do que faz" ou "é um desafio a ser superado", é possível interpretar que são sentidos próximos, isto é, um gosto especial no exercício da própria atividade em si mesma.

A relação que os entrevistados fazem de sentido do trabalho com a percepção de que sua contribuição é única e criativa, pode ser comparada à idéia apresentada por Morin (2002) de que o senso de responsabilidade percebido pelas pessoas leva à satisfação pessoal. Esta relação também pode se comparar ao conceito da Escola Sociotécnica de que trabalho com sentido permite autonomia e decisão. É importante salientar que o conceito de autonomia aqui utilizado é o da possibilidade de escolhas, de tomar decisões e se responsabilizar por elas.

A idéia de independência e sobrevivência, que surgiu como um tema na dimensão individual, também está em sintonia com os dados apresentados pelos autores pesquisados, porém traz uma dimensão diferente das tratadas por Morin e pela Escola Sociotécnica. Para os entrevistados, a remuneração almejada traz, muitas vezes, uma conotação libertadora: desde os mais jovens que se libertam dos pais, à mulher que é independente do marido e o dinheiro ganho com sacrifício hoje que permitirá obter uma vida mais tranqüila no futuro.

A Escola Sociotécnica aborda, dentre os elementos que dão sentido ao trabalho, a aprendizagem contínua. Tal tema é encontrado com muita frequiência na pesquisa realizada. Embora a remuneração esteja presente na maioria dos depoimentos dos entrevistados, muitos deles mostramse propensos a ganhar menos, desde que haja possibilidade de aprendizagem. A aprendizagem levaria a possibilidade de ganhos maiores no futuro. É importante salientar que na pesquisa, o crescimento ao qual se referem os entrevistados é o crescimento segundo níveis hierárquicos da organização.

A própria identidade das pessoas muitas vezes se confunde com seu trabalho. Morin (2002) cita que o processo 
de trabalho e seus resultados ajudam o indivíduo a formar sua identidade. Para este grupo estudado, muitos entrevistados citam não só seu trabalho, mas a própria empresa onde trabalham como fonte de orgulho, status e reconhecimento social.

Os autores pesquisados mencionam a utilidade como um fator que dá sentido ao trabalho. Em nossa pesquisa, os entrevistados atribuem sentido ao trabalho desde que tenha utilidade para a organização. Morin (2002) traz um elemento novo ao tema utilidade: de acordo com os administradores de Quebéc e da França, trabalho com sentido é aquele que além de ser útil é também realizado de maneira eficiente. Trata-se não só do fim do trabalho, mas também do processo pelo qual se chega a este fim. Este tema não foi observado nos entrevistados brasileiros.

Os relacionamentos interpessoais são também citados como temas de trabalho com significado. Morin (2002) dá às experiências vividas nas empresas uma conotação positiva, explicitando que no trabalho podem se desenvolver laços de afeição duráveis. Podemos considerar também que haja perda de significado do trabalho em situações nas quais as relações interpessoais possam ser fonte de frustração. Já a Escola Sociotécnica aborda o reconhecimento do trabalho realizado como fonte de significado. Os conceitos destas duas abordagens foram citados pelos entrevistados desta pesquisa.

É interessante notar que tanto a Escola Sociotécnica como as pesquisas realizadas por Morin (2002) incluem a dimensão social para trabalho que faz sentido. O que nossa pesquisa revela é que, a atribuição de sentido, relacionada à contribuição do trabalho para a sociedade, também está presente, porém o número de temas recorrentes encontrados nesta dimensão é muito menor. Ao analisar o conjunto das entrevistas, nos pareceu que os entrevistados mencionam de modo muito tênue que um trabalho faz sentido se contribuir para a sociedade.

\section{Considerações Finais}

O presente trabalho indica que há semelhanças entre as pesquisas internacionais sobre sentidos do trabalho e os temas recorrentes encontrados nesta pesquisa, porém, as especificidades do contexto brasileiro devem ser aprofundadas, já que a questão do trabalho como sobrevivência ficou em evidência mesmo considerando que se tratam de pessoas que dispõem de qualificação. Seria necessário realizar pesquisas em diferentes regiões nacionais. Outro importante aspecto que merece consideração é a verificação do sentido que homens e mulheres dão ao trabalho. A questão gênero pode ser fundamental em temas como identidade, independência e satisfação pessoal, por exemplo.

A idade dos entrevistados é outro fator fundamental que a pesquisa dá indícios de diferenciação. Mesmo dentro de nossa amostra, um grupo relativamente homogêneo, foi possível observar variações que poderiam ser atribuídas à idade e diferentes momentos de vida dos entrevistados. Pesquisar como grupos de idades distintas percebem trabalho com ou sem sentido contribuirá para o esclarecimento do tema.

Funções e cargos ocupados são aspectos que também merecem atenção de futuras pesquisas. O presente estudo, com estudantes de especialização em administração, pode ser comparado com profissionais de outras áreas na procura de temas recorrentes de sentido para o trabalho.

Os sentidos do trabalho precisam também de investigação em diferentes classes sociais, principalmente no Brasil, onde as desigualdades sociais são tão marcantes. Falar de remuneração e sobrevivência com estudantes de um curso de especialização em administração pode ser complemente distinto de falar sobre o mesmo tema com pessoas que não possuam tanta qualificação educacional. De fato, mesmo para esta amostra que dispõe de boa qualificação educacional, o sentido do trabalho foi fortemente associado à sobrevivência.

Em síntese, pode-se dizer que o tema merece ser mais pesquisado no país, face especialmente as transformações no mundo organizacional nestes últimos vinte anos, seja em abordagens mais descritivas como esta seja em pesquisas com orientações mais críticas.

\section{Notas}

Este trabalho foi apresentado no Encontro Nacional dos Programas de Pós-Graduação em Administração de Empresas (ENANPAD) de 2003. Os autores agradecem o apoio do GV Pesquisa para a realização deste trabalho e Alaíde Sipahi Dantas que ajudou na revisão final deste trabalho.

2 Segundo Hackman e Oldhan (1976), representantes da Escola Sociotécnica, um trabalho que tem sentido é importante, útil e legítimo para aquele que o realiza e apresenta três características fundamentais: (a) a variedade de tarefas; (b) a identificação de todo o processo do trabalho; e (c) ofeedback sobre seu desempenho nas atividades realizadas. Outros representantes da mesma escola são Trist (1978) e Emery (1964, 1976).

\section{Referências}

Alves, M. (1999). Absenteísmo e sofrimento no trabalho. In J. dos R. Sampaio (Ed.), Qualidade de vida, saúde mental e Psicologia social: Estudos contemporâneos II. São Paulo, SP: Casa do Psicólogo.

Antunes, R. (1995) Adeus ao trabalho? Ensaios sobre as metamorfoses e a centralidade do mundo do trabalho. Campinas, SP: Cortez.

Antunes, R. (1999). Os sentidos do trabalho: Ensaios sobre a afirmação e a negação do trabalho. São Paulo, SP: Boitempo.

Bauman,Z. (1998). O mal-estar da pós-modernidade. Rio de Janeiro, RJ: Jorge Zahar.

Beck, U. (1999). O que é globalização? Equívocos do globalismo: Respostas à globalização. São Paulo, SP: Paz e Terra.

Borges, L. H. (1997). Trabalho e doença mental: Reconhecimento social do nexo trabalho e doença mental. In J. F. da Silva \& S. 
Jardim (Eds.), A danação do trabalho: Organização do trabalho e sofrimento psíquico. Belo Horizonte, MG: TeCorá.

Borges, L. O. (1999, set./dez.). As concepções do trabalho: Um estudo de análise de conteúdo de dois periódicos de circulação nacional. RAC-Revista de Administração Contemporânea, Rio de Janeiro, 3(3), 81-108.

Borsoi, I. C. F. (2002). Os sentidos do trabalho na construção civil: O esforço alegre, sem a alegria do esforço. In M. das G. Jacques \& W. Codo (Eds.), Saúde mental e trabalho: Leituras (pp. 309324). Petrópolis, RJ: Vozes.

Castells, M. (1999). A sociedade em rede: Vol. 1. A era da informação: Economia, sociedade e cultura (2. ed.). São Paulo, SP: Paz e Terra

Codo, W. (2002). Um diagnóstico integrado do trabalho com ênfase em saúde mental. In M. das G. Jacques \& W. Codo (Eds.), Saúde mental e trabalho: Leituras (pp. 173-190). Petrópolis, RJ: Vozes.

Dejours, C. (1987). A loucura no trabalho: Estudos em psicopatologia do trabalho. São Paulo, SP: Cortez.

Dejours, C. (1999). Conferências brasileiras. São Paulo, SP: Fundap.

Dejours, C., \& Abdoucheli, E. (1994). Psicodinâmica do trabalho. São Paulo, SP: Atlas.

England, G. W., \& Whiteley, W. T. (1990). Cross-National Meanings of Working. In A. P. Brief \& W. R. Nord (Eds.), Meaning of occupational work (pp. 65-106). Toronto, Canadá: Lexington Books.

Emery, F. (1964). Report on the Hunsfoss project. London: Tavistock.

Emery, F. (1976). Future we are in. Leiden, Netherlands: Martinus Nijhoff.

Frankl, V. (1963). O sentido da vida. São Paulo, SP: Martins Fontes.

Freud, S. (1997). Mal estarna civilização. Rio de Janeiro, RJ: Imago.

Harvey, D. (1993). Condição Pós-Moderna: Uma pesquisa sobre as origens da mudança cultural. São Paulo, SP: Loyola.

Hackman, J. R., \& Oldham, G.R. (1976). Motivation thorough the design of work: Tes ot a theory. Organizational Behavior and Human Performance, 16, 250-279.

Ibañez, T. (1997). Why a critical social psychology? In T. Ibanez \& L. Iniguez (Eds.), Critical social psychology (pp. 27-41). Thousand Oaks, CA: Sage.

Jacques, E. (1978). Des systèmes sociaux comme defenses contre l'anxiété dépressive et l'anxiété de persécution. In A. Lévy (Ed.), Psychologie sociale: textes fondamentaux anglais et américains (Vol. 2, pp. 546-565). Paris: Dunod.

Jacques, M. das G. (2002). “Doença dos nervos": Uma expressão da relação entre saúde/doença mental. In M. das G. Jacques \& W. Codo (Eds.), Saúde mental e trabalho: Leituras (pp. 98-111). Petrópolis, RJ: Vozes.

Meaning of Work International Research Team. (1987). The meaning of work. London: Academic Press.

Morin, E. (1996). L'efficacité organisationnelle et sens du travail. In T. Pauchaunt (Ed.), La quête du sens: gerer nos organizations pour la snaté des personnes, de nos sociètés et de la nature (pp. 257-286). Quebec, Canadá: Editions de l'organisation.

Morin, E. (1997). Le sens du travail pour des gestionnaires francophones. Revue Psychologie du Travail e des Organizations, $3(2 / 3), 26-45$.

Morin, E. (2002). Os sentidos do trabalho. In T. Wood (Ed.), Gestão empresarial: O fator humano (pp. 13-34). São Paulo, SP: Atlas.
Pauchaunt, T. (Ed.). (1996). La quête du sens: gerernos organizations pour la snaté des personnes, de nos sociètés et de la nature. Quebec, Canadá: Editions de l'organisation.

Rifkin, J. (1995). O fim dos empregos: O declínio inevitável dos níveis dos empregos e a redução da força global de trabalho. São Paulo, SP: Makron Books.

Schaff, A. (1995). A sociedade informática: As consequiências sociais da segunda revolução industrial. São Paulo, SP: Brasiliense.

Seligmann-Silva, E. (1994). Desgaste mental no trabalho dominado. São Paulo, SP: Cortez.

Seligmann-Silva, E. (1997). A interface desemprego prolongado e saúde psicossocial. In J. Silva \& S. Jardim (Eds.), A danação do trabalho (pp.19-63). Rio de Janeiro, RJ: TeCorá.

Sennet, R. (1999). A corrosão do caráter: conseqüências pessoais do trabalho no novo capitalismo. Rio de Janeiro, RJ: Record.

Spink, M. J. (Ed.). (1999). Práticas discursivas e produção de sentidos no cotidiano: Aproximações teóricas e metodológicas. São Paulo, SP: Cortez.

Trist, E. (1978). Adapting to a changing work. Labour Gazette, 78, 14-20.

Weick, K. E. (2000). Emergent change as a universal in organizations. In M. Beer \& N. Nohria (Eds.), Breaking the code of change (pp. 223-241). Boston: Harvard Business School Press.

Estelle Morin é psicóloga, com mestrado e doutorado em Psicologia Organizacional e professora titular da HEC - Montreal e coordenadora e diretora do Centro de pesquisa e intervenção para o trabalho, eficácia organizacional e saúde (CRITEOS). Seus interesses de pesquisa voltam-se para os sentidos do trabalho e seus impactos na saúde e na eficácia organizacional.

Maria José Tonelli é psicóloga, com mestrado e doutorado em Psicologia Social. É professora adjunta da Fundação GetúlioVargas (FGV-SP) e seus interesses de pesquisa voltam-se para a construção de práticas organizativas nas empresas brasileiras. Endereço para correspondência: Rua Itapeva, $474-11^{\circ}$ andar. CEP 01332-000 - São Paulo, SP maria.jose.tonelli@fgv.br

Ana Luisa Vieira Pliopas é biológa, com mestrado em Administração de Empresas pela FGV-SP. Trabalha há muitos anos na área de Recursos Humanos, e seus interesses de pesquisa estão ligados às transformações de processos e práticas de recursos humanos nas empresas.

\section{O trabalho e seus sentidos}

Estelle Morin, Maria José Tonelli e Ana Luisa Vieira Pliopas

Recebido: 30/11/06

$1^{\text {a }}$ revisão: 09/04/07

$2^{a}$ revisão: 01/06/07

Aceite final: 01/06/07 